\title{
Complications after lower body contouring surgery due to massive weight loss unaffected by weight loss method
}

\author{
Susanna Pajula, M.D. ${ }^{a, b, *}$, Janne Jyränki, M.D. ${ }^{b}$, \\ Erkki Tukiainen, M.D., Ph.D ${ }^{\mathrm{b}}$, Virve Koljonen, M.D, Ph.D ${ }^{\mathrm{b}}$ \\ a Department of Plastic and General Surgery Turku University Hospital, Turku, Finland \\ ${ }^{\mathrm{b}}$ Department of Plastic Surgery, University of Helsinki and Helsinki University Hospital, Helsinki, Finland
}

Received 29 June 2018; accepted 2 December 2018

Available online $\mathrm{xxx}$

\section{KEYWORDS \\ Body contouring; \\ Weight loss; \\ Belt lipectomy; \\ Abdominoplasty}

Summary Body contouring surgery following massive weight loss positively affects a patient's quality of life. However, the procedure is prone to complications. Herein, we stratified complications timewise. Furthermore, we examined whether the weight loss method - bariatric surgery or lifestyle changes - affected the frequency or severity of complications. In this single-centre retrospective analysis, we included 158 patients with massive weight loss undergoing body contouring surgery between 2009 and 2015. We recorded 96 complications in 80 patients, with an overall rate of $51 \%$. Most complications $(80.2 \%)$ were minor (Clavien-Dindo grades 1 and 2 ) and superficial wound infections. Immediate complications (0-24 hours postoperation) affected $8.3 \%$ of patients, with early complications (1-7 post-operative days) affecting $16.7 \%$ of them and late complications (8-30 post-operative days) affecting $58.3 \%$ of them. We found no statistical difference in complication rates when comparing bariatric and nonbariatric patients. Older age $(p=0.042)$ at operation is associated with an increased risk for immediate haematoma or bleeding requiring surgery. Among early complications, a high maximum weight $(p=0.035)$ and a high preoperative weight $(p=0.0053)$ significantly correlated with a haematoma or bleeding requiring surgery. For late complications, seroma correlated with older age $(p=0.0061)$. Complications are primarily minor and non-life threatening after body contouring surgery because of frequent massive weight loss. Here, no particular subgroup of massive weight loss patients appeared more prone to complications. Thus, for each patient, the risks associated with body contouring surgery following massive weight loss should be considered individually.

(C) 2018 British Association of Plastic, Reconstructive and Aesthetic Surgeons. Published by Elsevier Ltd. All rights reserved.

\footnotetext{
* Correspondence to: Dr. Susanna Pajula, Department of Plastic and General Surgery, Kiinanmyllynkatu 4-8, 20521 Turku, Finland.

E-mail address: susanna.pajula@tyks.fi (S. Pajula).
}

\section{Introduction}

Loose, hanging skin is a well-known consequence following massive weight loss. ${ }^{1}$ Excess skin folds may lead to 
intertrigo, ulceration, infection and oedema. ${ }^{2,3}$ These issues may cause physical problems hindering daily life, and patients may find excess skin psychologically and socially inhibiting. ${ }^{4-6}$ Furthermore, excess skin may also cause difficulty in using well-fitting clothes and greatly affect intimacy, possibly triggering major body image dissatisfaction or depression. ${ }^{4,7}$

Loose, excess skin is most commonly located in the midbody, ${ }^{2,8}$ although it can be present in many other regions of the body. ${ }^{9}$ These contour deformities are resistant to exercise and diet. ${ }^{8}$ The only efficient intervention is removing excess skin surgically. ${ }^{8}$ Thus, procedures focusing on the abdomen and lower back or buttocks area are common following massive weight loss. ${ }^{8,10}$ Along the anterior lower body, abdominoplasty represents the most common procedure to reconstruct contour deformities. ${ }^{11-13}$ If the posterior part of the lower body is also affected, a circumferential procedure also known as a belt lipectomy is employed. ${ }^{11}$ Whilst a large amount of variations exist across procedures, ${ }^{14-16}$ ultimately, dermolipectomy is employed to excise excess skin.

According to the literature, post-operative complications in body contouring surgery occur because of frequent massive weight loss, ranging from $28 \%$ to $78 \% .{ }^{11-13,20}$ The majority of complications are minor. ${ }^{11,12,20}$ Significant risk factors for post-operative complications following body contouring surgery include a high pre-surgical BMI, a high American Society of Anesthesiologists (ASA) score, the amount of excess weight loss, the amount of tissue removed, intraoperative hypothermia, male gender, older age, smoking and comorbidities such as diabetes and hypertension. ${ }^{21-26}$ Furthermore, bariatric surgery itself induces malabsorption and nutritional imbalance, ${ }^{17}$ thus increasing the complication rate in post-bariatric patients. ${ }^{18,19}$ Particularly, postbariatric surgery patients have a $60 \%$ to $87 \%$ increased risk of complications compared with non-bariatric surgery patients who lost weight through changing their dietary habits or through exercise. ${ }^{27}$

Lifestyle changes along with diet for weight loss and increased exercise is foundation to any weight loss ${ }^{28}$. However, in advanced cases, bariatric surgery, especially laparoscopic procedures, results in weight loss with reduced complication rates ${ }^{28}$. Bariatric procedures can be categorised as procedures restricting the amount of food such as gastric banding and sleeve gastrectomy, thereby causing malabsorption such as biliopancreatic diversion with duodenal switch, or by a combination of both restriction and malabsorption such as Roux-en-Y gastric bypass. The current study aimed to examine complications following lower body contouring surgery due to massive weight loss in a single centre. We sought to stratify the complications according to their severity and time of occurrence. Furthermore, we aimed to study whether the method of weight loss - either bariatric surgery or lifestyle change - affected the frequency and severity of complications.

\section{Patients and methods}

The hospital's institutional review board approved this retrospective chart review study and its protocol.
The hospital's electronic database Opera ${ }^{\circledR}$ within the Department of Plastic Surgery, Helsinki, Finland, was queried for patients who underwent either abdominoplasty or belt lipectomy during the period from January 1st 2009 to December 31st 2015. We included only patients with massive weight loss through either bariatric surgery or lifestyle change. We excluded patients whose indication for abdominoplasty was post-pregnancy.

Computerised medical records were reviewed in detail, and the data reviewed for each patient included the following: age, gender, comorbidities (such as arterial hypertension and type 2 diabetes dyslipidaemia), former abdominal surgery, smoking (current smoker, former smoker and nonsmoker), highest lifetime weight and BMI and weight loss method (surgical or non-surgical).

The body contouring surgery specific variables consisted of age, weight and BMI on the body contouring surgery day; the specific procedure and the operative time for body contouring. We also noted the haemoglobin rate before and after surgery, the duration of hospital stay, institutional discharge and any complications. The documentation of complications consisted of wound infections, wound dehiscence, seroma, haematoma or wound bleeding, deep-tissue infection, skin necrosis, deep vein thrombosis, embolism and sepsis.

We grouped complications into four categories on the basis of their occurrence: immediate complications occurred 0 to 24 hours after the body contouring procedure, early complications occurred 1 to 7 days after surgery, late complications from 8 to 30 days after the procedure and complications requiring readmission.

Patients were divided into two groups using the weight loss method employed. Those who lost weight through bariatric surgery were placed in the bariatric group and those who lost weight through a lifestyle change were placed in the non-bariatric group.

Finally, all complications were divided into five grades according to the Clavien-Dindo classification. ${ }^{29}$

\section{Statistical methods and analysis}

Statistical analysis was conducted using NCSS 2007 (NCSS Statistical Software, Kaysville, UT, USA) and SPSS Statistics version 19.0 (IBM Corporation, NY, USA). We considered $p$ values of less than 0.05 as statistically significant.

The comparisons between the bariatric and non-bariatric groups were analysed using the Chi-square test, whereas continuous variables were analysed using Student's t-test and the Mann-Whitney U-test. Risk factors for complications were analysed using Fisher's exact test.

To study the risk factors for any complication occurring at any time point, we employed chi-square test for categorised risk factors - gender, method of weight loss, diabetes, arterial hypertension, dyslipidaemia, former abdominal surgery and smoking. Many risk factors - age, highest lifetime weight and $\mathrm{BMI}$, weight and $\mathrm{BMI}$ on the body contouring surgery day and operative time for body contouring - were analysed with the Mann-Whitney test.

To analyse further the method of weight loss on the rate of complications, we employed the matched-pairs test. The patients were stratified according to the weight loss method 
Table 1 Demographic characteristics of massive weight loss in 158 patients who underwent lower body contouring surgery after massive weight loss. $\mathrm{p}$ values denote the correlation between bariatric and nonbariatric patients.

\begin{tabular}{|c|c|c|c|c|}
\hline & All & Bariatric & Nonbariatric & $p$ value \\
\hline $\mathbf{N}$ & 158 & $90(57.1)$ & $68(43.3)$ & 0.388137 \\
\hline Female (\%) & $117(74.1)$ & $69(76.7)$ & $48(70.6)$ & \\
\hline Male (\%) & $41(25.9)$ & $21(23.3)$ & $20(29.4)$ & \\
\hline \multicolumn{5}{|c|}{ Mean age in years (range) at body contouring surgery } \\
\hline All & $44.8(22-72)$ & $46.0(24-64)$ & $43.0(22-72)$ & $0.090989 *$ \\
\hline Male & $46.7(22-72)$ & $48.9(24-64)$ & $44.3(22-72)$ & \\
\hline Female & $44.1(22-72)$ & $45.1(24-62)$ & $42.5(22-72)$ & \\
\hline Maximum weight, mean kg (range) & $136.5(79-285)$ & $139.5(96-285)$ & $132.4(79-267)$ & 0.11607 \\
\hline Maximum BMI, mean (range) & $47.6(31.90-90.97)$ & $49.0(37-90.97)$ & $45.8(31.90-82.41)$ & $0.00693^{*}$ \\
\hline \multicolumn{5}{|c|}{ Outpatient visit for body contouring surgery } \\
\hline Weight, mean kg (range) & $83.3(55-150)$ & $83.2(55-150)$ & $83.5(60-132)$ & 0.828916 \\
\hline \multicolumn{5}{|l|}{ BMI, mean (range) } \\
\hline Weight loss, mean kg (range) & $54.4(9.4-157.0)$ & $56.8(27.5-135)$ & $51.2(9.4-157)$ & $0.0124^{*}$ \\
\hline \multicolumn{5}{|l|}{ Risk factors for complications } \\
\hline Diabetes mellitus (\%) & $39(24.7)$ & $28(31.1)$ & $11(16.2)$ & $0.0311105^{*}$ \\
\hline Arterial hypertension (\%) & $63(39.9)$ & $45(50)$ & $18(25.6)$ & $0.002783^{*}$ \\
\hline Hyperlipidaemia & $37(23.4 \%)$ & $26(28.9 \%)$ & $11(16.2 \%)$ & 0.061725 \\
\hline \multicolumn{5}{|l|}{ Smoking status } \\
\hline Active smoker & $28(17.7 \%)$ & $21(23.3 \%)$ & $7(10.3 \%)$ & $0.030483^{*}$ \\
\hline Ex-smoker & $22(13.9 \%)$ & $15(16.7 \%$ & $7(10.3 \%)$ & \\
\hline Abdomen surgery before & $69(43.7 \%)$ & $39(43.3 \%)$ & $30(44.1 \%)$ & 0.921600 \\
\hline
\end{tabular}

and were matched with age, \pm 5 years, and gender. $\mathrm{McNe}$ mar's test was used to examine the paired nominal data, and statistically significant $\mathrm{p}$-values denote differences in the cohorts.

\section{Results}

\section{All patients}

The specific inclusion criteria resulted in a sample of $158 \mathrm{pa}-$ tients, consisting of 117 women (74.1\%) and 41 men (25.9\%), with age ranging from 22 to 72 years and a mean age of 44.8 years. In total, 90 patients (57\%) lost weight through bariatric surgery and 68 (43\%) through lifestyle changes.

Table 1 summarises patient demographic characteristics and provides a comparison between the two groups. For all patients, the mean highest lifetime weight was $136.5 \mathrm{~kg}$ and the mean highest lifetime BMI was $47.6 \mathrm{~kg} / \mathrm{m}^{2}$, with a mean weight loss of $54.4 \mathrm{~kg}$. The majority of them, i.e. 112 patients (70.9\%), underwent abdominoplasty and 46 (29.1\%) had a belt lipectomy. Twenty-eight of them (17.7\%) were current smokers, 63 (39.9\%) had hypertension, 39 (24.7\%) had diabetes and 37 (23.4\%) had hyperlipidaemia.

\section{Bariatric group}

A total of 90 patients $(57.1 \%)$ were included in the bariatric group, with a mean age of 46 years, ranging from 24 to 64 years. The mean time between bariatric surgery and body contouring surgery was 2.69 years. The most common bariatric procedure was gastric bypass in 75 patients $(83.3 \%)$, followed by gastric sleeve surgery in 14 patients
(15.5\%), and gastric balloon surgery in 1 (1.1\%). The mean highest lifetime weight was $139.5 \mathrm{~kg}$ and the mean highest lifetime BMI was $49.0 \mathrm{~kg} / \mathrm{m}^{2}$. Mean weight loss in the bariatric group reached $56.8 \mathrm{~kg}$, ranging from 27.5 to 135 $\mathrm{kg}$. The mean weight at the first plastic surgery outpatient clinic visit was $83.2 \mathrm{~kg}$, ranging from 55 to $150 \mathrm{~kg}$. In total, $60(66.7 \%)$ patients underwent abdominoplasty and 30 (33.3\%) patients underwent belt lipectomy.

\section{Non-bariatric group}

There were 68 patients $(43.3 \%)$ in the non-bariatric group, with a mean age of 43 years, ranging from 22 to 72 years. The mean highest lifetime weight reached $132.4 \mathrm{~kg}$ and the mean highest lifetime BMI was $45.8 \mathrm{~kg} / \mathrm{m}^{2}$. Mean weight loss reached $51.2 \mathrm{~kg}$, ranging from 9.4 to $157 \mathrm{~kg}$. The mean weight at first plastic surgery outpatient clinic visit was 83.5 $\mathrm{kg}$, ranging from 60 to $132 \mathrm{~kg}$. In total, 52 (76.5\%) patients underwent abdominoplasty and $16(23.5 \%)$ patients underwent belt lipectomy.

\section{Comparison of the bariatric and non-bariatric groups}

Using the Chi-square test, we found no significant difference between the bariatric and non-bariatric groups with regard to the mean age $(p=0.090)$, maximum weight before weight loss $(p=0.116)$, dyslipidaemia $(p=0.0167)$, arterial hypertension $(p=0.0167)$ or any abdominal surgery before contouring surgery $(p=0.92)$. A comparison of groups showed significant differences in the maximum 
Table 2 Number and stratification of recorded complications, $\mathrm{n}=96$.

\begin{tabular}{|c|c|c|c|c|c|c|}
\hline & & All, n (\%) & $\begin{array}{l}\text { Immediate } \\
\text { complication, } \mathrm{n}\end{array}$ & $\begin{array}{l}\text { Early } \\
\text { complication, } \mathrm{n}\end{array}$ & $\begin{array}{l}\text { Late } \\
\text { complication, } \mathrm{n}\end{array}$ & $\begin{array}{l}>30 \text { postoperative } \\
\text { days, } n\end{array}$ \\
\hline \multirow[t]{4}{*}{ Wound related } & Wound infections & $18(18.8)$ & 0 & 1 & 14 & 3 \\
\hline & Wound dehiscence & $3(3.1)$ & 0 & 0 & 3 & 0 \\
\hline & Skin necrosis & $3(3.1)$ & 0 & 0 & 2 & 1 \\
\hline & Suture fistula & $12(12.5)$ & 0 & 0 & 5 & 7 \\
\hline \multirow[t]{3}{*}{$\begin{array}{l}\text { Bleeding } \\
\text { related }\end{array}$} & $\begin{array}{l}\text { Post-operative } \\
\text { hematoma, not } \\
\text { requiring any } \\
\text { intervention }\end{array}$ & $5(5.2)$ & 0 & 2 & 3 & 0 \\
\hline & $\begin{array}{l}\text { Post-operative } \\
\text { haematoma, needing } \\
\text { transfusion }\end{array}$ & $8(8.3)$ & 4 & 4 & 0 & 0 \\
\hline & $\begin{array}{l}\text { Post-operative } \\
\text { bleeding, with } \\
\text { surgical intervention }\end{array}$ & $9(9.4)$ & 4 & 5 & 0 & 0 \\
\hline Seroma & Seroma & $23(24.0)$ & 0 & 2 & 18 & 3 \\
\hline Infectious & Deep tissue infection & $13(13.5)$ & 0 & 2 & 10 & 1 \\
\hline complications & Systemic infection & $1(1)$ & 0 & 0 & 1 & 0 \\
\hline Pain & Pain & $1(1)$ & 0 & 0 & 0 & 1 \\
\hline
\end{tabular}

Table 3 Complications stratified by Clavien-Dindo classification.

\begin{tabular}{|c|c|c|c|c|c|c|}
\hline & I & II & Illa & IIIb & $\mathrm{IVa}$ & $\mathrm{IVb}$ \\
\hline Wound infection $(n=18)$ & 4 & 14 & 0 & 0 & 0 & 0 \\
\hline Wound dehiscence $(n=3)$ & 1 & 2 & 0 & 0 & 0 & 0 \\
\hline Post-operative haematoma $(n=22)$ & 5 & 8 & 0 & 9 & 0 & 0 \\
\hline Seroma $(n=23)$ & 22 & 0 & 0 & 1 & 0 & 0 \\
\hline Skin necrosis $(n=3)$ & 1 & 0 & 2 & 0 & 0 & 0 \\
\hline Deep tissue infection $(n=13)$ & 0 & 6 & 3 & 4 & 0 & 0 \\
\hline Systemic infection $(n=1)$ & 0 & 1 & 0 & 0 & 0 & 0 \\
\hline Fistula $(n=12)$ & 12 & 0 & 0 & 0 & 0 & 0 \\
\hline Post operative pain $(n=1)$ & 1 & 0 & 0 & 0 & 0 & 0 \\
\hline
\end{tabular}

BMI $(p=0.00693)$ and total weight loss $(p=0.0124)$. Furthermore, the non-bariatric group contained fewer patients with diabetes $(p=0.0311)$, less arterial hypertension $(p=0.0028)$ and fewer current smokers $(p=0.03048)$.

\section{All complications}

We identified a total of 96 complications in 80 patients (Table 2 ). Thus, the overall complication rate was $51 \%$. In the majority, i.e. 64 patients $(80 \%)$, only one complication was recorded, followed by 16 patients (20\%) with two complications. The complications were graded as follows using the Clavien-Dindo classification: 46 grade 1 (47.9\%), 31 grade 2 (32.3\%), 5 grade $3 a(5.2 \%)$ and 14 grade $3 b$ (14.6\%). No grade 4 or grade 5 complications were recorded (Table 3).

Most complications that occurred in 77 (80.2\%) cases were minor, which were Clavien-Dindo grades 1 and 2. Major complications, Clavien-Dindo grades $3 \mathrm{a}$ and $3 \mathrm{~b}$, occurred in 19 (19.8\%) cases.

Complications due to infections were recorded in 32 (33\%) cases, thus representing infections as the most com- mon cause. Superficial wound infections were recorded in $18(18.8 \%)$ cases, deep-tissue infections occurred in 13 (13.5\%) cases and systemic infection occurred in 1 (1\%) case.

The second most common complication was seroma, recorded in $23(24 \%)$ cases. Most seromas occurred for a minimum of 8 days post-operatively. Two cases of seroma, however, occurred before 8 post-operative days and three cases occurred 30 days after the surgery.

Post-operative bleeding-related complications represented the third most common occurrence, found in 22 cases $(23 \%)$. A post-operative haematoma was noted in five cases and was left to resolve without any intervention. In nine cases, post-operative bleeding needed surgical intervention with a blood transfusion, whereas eight cases relied only on a blood transfusion to resolve.

Immediate complications (0-24 hours post-operatively) were recorded in 8 (8.3\%) cases. Early complications (1-7 days post-operatively) occurred in $16(16.7 \%)$ cases and late complications (8-30 days post-operatively) occurred in 56 (58.3\%) cases. Complications that occurred for more than 30 days post-operatively were recorded in $16(16.7 \%)$ cases, typically due to suture fistula in seven cases. 
Table 4 Complications stratified by the method of weight loss and lower body contouring surgery.

\begin{tabular}{lll}
\hline & $\begin{array}{l}\text { Bariatric group } \\
\text { complications, } \mathrm{n}=31(\%)\end{array}$ & $\begin{array}{l}\text { Non-bariatric group } \\
\text { complications, } \mathrm{n}=34(\%)\end{array}$ \\
\hline Wound infections & $3(10)$ & $9(26)$ \\
Wound dehiscence & $1(3)$ & $2(6)$ \\
Skin necrosis & $2(6)$ & $1(3)$ \\
Fistula & $6(19)$ & $1(3)$ \\
Post-operative haematoma & $5(16)$ & $5(15)$ \\
Seroma & $8(26)$ & $9(26)$ \\
Deep tissue infection & $5(16)$ & $7(21)$ \\
Systemic infection & $1(3)$ & $0(0)$ \\
& Bariatric group & Non-bariatric group \\
& complications, $\mathrm{n}=19$ & complications, $\mathrm{n}=10$ \\
$(\%)$ & $1(10)$ \\
Wound infection & $(\%)$ & $0(0)$ \\
Wound dehiscence & $5(26)$ & $0(0)$ \\
Skin necrosis & $0(0)$ & $3(30)$ \\
Fistula & $0(0)$ & $6(60)$ \\
Post-operative haematoma & $1(5)$ & $0(0)$ \\
Seroma & $6(32)$ & $0(0)$ \\
Deep tissue infection & $6(32)$ & $0(0)$ \\
Systemic infection & $1(5)$ &
\end{tabular}

\section{Risk factors for complications}

We found no statistical difference in terms of the complications when comparing the bariatric and non-bariatric groups. Statistically significant risk factors consisted of an older age $(p=0.042)$ at operation for immediate haematoma or bleeding needing surgical intervention. For early complications, a high maximum weight $(p=0.035)$ and a high preoperative weight $(p=0.0053)$ significantly correlated with a haematoma or bleeding needing surgical intervention. For late complications, the occurrence of seroma correlated with older age $(p=0.0061)$. We failed to determine any statistically significant risk factors for any complication at any time point.

For matched-pairs test, we established two groups with 45 patients by the method of weight loss, age, and gender match. The statistical pair analysis did not reveal differences in complications by the method of weight loss.

\section{Comparison of abdominoplasty and belt lipectomy}

We found no differences in wound-related complications. However, we found a slight statistical difference in the rates of post-operative bleeding and surgical intervention in the belt lipectomy group $(p=0.0043)$. Table 4 summarises the complications according to weight loss methods and lower body contouring surgery procedure.

\section{Discussion}

Here, we described our experience with lower body contouring surgery complications among patients with massive weight loss, thus contributing to the literature in this study of 158 patients. In agreement with previous studies, our overall complication rate was $51.3 \%$. The majority $(80.2 \%)$ of complications consisted of minor issues and grade 1 and 2 complications according to the Clavien-Dindo classification. Furthermore, most of our patients experienced only one complication. We recorded no life-threatening complications or deaths.

Our most common complications were superficial infection-related complications, followed by seromas and bleeding. Our findings agree well with those reported in previous studies. In the previous literature, the single most common post-operative complication following lower body contouring surgery consists of seromas, thus accounting for approximately $5 \%$ to $15 \%$ of all complications, ${ }^{11-13,22}$ followed by wound-related problems, ${ }^{22}$ such as dehiscence ${ }^{11,20}$ and skin-edge necrosis. ${ }^{13}$ Other complications include haematomas, lymphoceles, deep vein thromboembolism, pulmonary embolism, lymphedema, post-operative anaemia and nerve injuries. ${ }^{20-23,30}$ When comparing abdominoplasty and belt lipectomy, we found no statistically significant difference in wound healing complication rates. Thus, given our current results, we conclude that most patients would benefit from belt lipectomy - that is, correcting both the anterior and posterior parts of the body.

Body contouring after massive weight loss is prone to complications whereby the proportion of all complications is typically high reaching up to $70 \% .^{11,12,20,31-33}$ It seems that the vast majority of complications are minor. However, only a few recent studies ${ }^{12,20}$ have applied a systematic approach to classify complications such as the Clavien-Dindo classification. In our study, more than $75 \%$ of the complications were classified as late, that is, occurring 7 to 30 days postoperatively. These primarily consisted of seromas or wound problems.

In this study, non-bariatric patients comprised $43 \%$ of all patients. This figure is somewhat larger than those obtained in previous studies, whereby the percentage of non- 
bariatric patients typically ranges from $9 \%$ to $18 \% .{ }^{20,31,33,34}$ However, contrary to previous studies, wherein postbariatric surgery patients have a $60 \%$ to $87 \%$ increased risk of complications compared with non-bariatric patients who lost weight through changes in dietary habits or through exercise, ${ }^{27}$ our results contradict this somewhat. Our groups comparing bariatric and non-bariatric patients were similar in terms of both weight and weight loss. Although the two groups may seem heterogeneous, our statistical analyses showed that the groups were similar regarding the complications.

Changes in diet and lifestyle habits play an important role in weight loss. Some obese individuals are not able to lose weight through dietary changes and through exercise, and hence, they must resort to bariatric surgery. Furthermore, bariatric surgery represents the most effective treatment for morbid obesity. Following bariatric surgery, individuals tend to experience significant improvements in obesity-related comorbidities. ${ }^{35}$ Thus, in this study, we found no previous comorbidities affecting or presenting as risk factors for complications. Instead, we found that older age, a higher maximum weight and a higher preoperative weight were risk factors for complications such as bleeding and seroma.

We should also consider the limitations of this study. First, the limited number of patients and the drawbacks inherent to retrospective studies represent the foremost limitations to our study. Reviewing clinical diagnostic impressions from medical records, specifically those not intended for research, is prone to investigator bias. However, the strength of this study lies in the comparability of the bariatric and non-bariatric groups and the comprehensive documentation of complications across all patients.

To conclude, complications following body contouring surgery are due to frequent massive weight loss, although most are minor and non-life threatening. In this study, we found no particular subgroup of patients with massive weight loss particularly prone to complications. Hence, for each patient, the risks for body contouring surgery following massive weight loss should be considered individually. In particular, our results also favour the comprehensive contouring of both the anterior and posterior parts of the body.

\section{Conflict of Interest Statement}

All authors declare no financial conflicts of interest with regard to the data presented in this manuscript. This research was funded by departmental sources only.

\section{References}

1. Kitzinger HB, Abayev S, Pittermann A, et al. After massive weight loss: patients' expectations of body contouring surgery. Obes Surg 2012;22:544-8.

2. Biorserud C, Olbers T, Fagevik Olsen M. Patients' experience of surplus skin after laparoscopic gastric bypass. Obes Surg 2011;21:273-7.

3. Bossert RP, Rubin JP. Evaluation of the weight loss patient presenting for plastic surgery consultation. Plast Reconstr Surg 2012;130:1361-9.
4. Gilmartin J. Body image concerns amongst massive weight loss patients. J Clin Nurs 2013;22:1299-309.

5. Staalesen T, Fagevik Olsen M, Elander A. Experience of excess skin and desire for body contouring surgery in post-bariatric patients. Obes Surg 2013;23:1632-44.

6. Biorserud C, Fagevik Olsen M, Elander A, Wiklund M. Objective measurements of excess skin in post bariatric patients-inter-rater reliability. J Plast Surg Hand Surg 2016;50:68-73.

7. Klassen AF, Cano SJ, Scott A, Johnson J, Pusic AL. Satisfaction and quality-of-life issues in body contouring surgery patients: a qualitative study. Obes Surg 2012;22:1527-34.

8. Colwell AS. Current concepts in post-bariatric body contouring. Obes Surg 2010;20:1178-82.

9. Song AY, Jean RD, Hurwitz DJ, et al. A classification of contour deformities after bariatric weight loss: the Pittsburgh Rating Scale. Plast Reconstr Surg 2005;116:1535-44 discussion 45-6.

10. Tremp M, Delko T, Kraljevic M, et al. Outcome in bodycontouring surgery after massive weight loss: A prospective matched single-blind study. J Plast Reconstr Aesthet Surg 2015;68:1410-16.

11. Garcia Botero A, Garcia Wenninger M, Fernandez Loaiza D. Complications After Body Contouring Surgery in Postbariatric Patients. Ann Plast Surg 2017;79:293-7.

12. van der Beek ES, van der Molen AM, van Ramshorst B. Complications after body contouring surgery in post-bariatric patients: the importance of a stable weight close to normal. Obes Facts 2011;4:61-6.

13. Parvizi D, Friedl $H$, Wurzer $P$, et al. A Multiple Regression Analysis of Postoperative Complications After Body-Contouring Surgery: a Retrospective Analysis of 205 Patients: Regression Analysis of Complications. Obes Surg 2015;25:1482-90.

14. Modarressi A, Meia Ruegg E, Bezzola T, Pittet-Cuenod B. Circular abdominoplasty after massive weight loss: Is it a risky procedure? J Plast Reconstr Aesthet Surg 2016;69:1497-505.

15. Mejia JA, Cardenas Castellanos YA. Extended abdominoplasty: applications and a new classification system for abdominoplasty. Aesthetic Plast Surg 2012;36:278-84.

16. Friedman T, O'Brien Coon D, Michaels J, et al. Fleur-de-Lis abdominoplasty: a safe alternative to traditional abdominoplasty for the massive weight loss patient. Plast Reconstr Surg 2010;125:1525-35.

17. Reiffel AJ, Jimenez N, Burrell WA, et al. Body contouring after bariatric surgery: how much is really being done? Ann Plast Surg 2013;70:350-3.

18. Wong MS. Post-Bariatric Body Contouring Surgery After Weight Loss: Lessons Learned From an Obesity Epidemic in the United States. Ann Plast Surg 2016;77(Suppl 1):S53-9.

19. Coriddi MR, Koltz PF, Chen R, Gusenoff JA. Changes in quality of life and functional status following abdominal contouring in the massive weight loss population. Plast Reconstr Surg 2011;128:520-6.

20. Poodt IG, van Dijk MM, Klein S, Hoogbergen MM. Complications of Lower Body Lift Surgery in Postbariatric Patients. Plast Reconstr Surg Glob Open 2016;4:e1030.

21. Winocour J, Gupta V, Ramirez JR, et al. Abdominoplasty: Risk Factors, Complication Rates, and Safety of Combined Procedures. Plast Reconstr Surg 2015;136:597e-606e.

22. Greco JA 3rd, Castaldo ET, Nanney LB, et al. The effect of weight loss surgery and body mass index on wound complications after abdominal contouring operations. Ann Plast Surg 2008;61:235-42.

23. Neaman KC, Hansen JE. Analysis of complications from abdominoplasty: a review of 206 cases at a university hospital. Ann Plast Surg 2007;58:292-8.

24. Rogliani M, Gentile P, Silvi E, Labardi L, Cervelli V. Abdominal dermolipectomy: risks and complications in smokers treated from 2004 to october of 2006. Plast Reconstr Surg 2008;122:85e-86e. 
25. Gravante G, Araco A, Sorge R, et al. Wound infections in post-bariatric patients undergoing body contouring abdominoplasty: the role of smoking. Obes Surg 2007;17:1325-31.

26. Coon D, Michaels Jt, Gusenoff JA, et al. Hypothermia and complications in postbariatric body contouring. Plast Reconstr Surg 2012;130:443-8.

27. Hasanbegovic E, Sorensen JA. Complications following body contouring surgery after massive weight loss: a meta-analysis. J Plast Reconstr Aesthet Surg 2014;67:295-301.

28. Bray GA, Fruhbeck G, Ryan DH, Wilding JP. Management of obesity. Lancet 2016;387:1947-56.

29. Clavien PA, Barkun J, de Oliveira ML, et al. The Clavien-Dindo classification of surgical complications: five-year experience. Ann Surg 2009;250:187-96.

30. Montano-Pedroso JC, Garcia EB, Omonte IR, Rocha MG, Ferreira LM. Hematological variables and iron status in abdominoplasty after bariatric surgery. Obes Surg 2013;23:7-16.
31. Kitzinger HB, Cakl T, Wenger R, et al. Prospective study on complications following a lower body lift after massive weight loss. J Plast Reconstr Aesthet Surg 2013;66:231-8.

32. Nemerofsky RB, Oliak DA, Capella JF. Body lift: an account of 200 consecutive cases in the massive weight loss patient. Plast Reconstr Surg 2006;117:414-30.

33. de Kerviler S, Husler R, Banic A, Constantinescu MA. Body contouring surgery following bariatric surgery and dietetically induced massive weight reduction: a risk analysis. Obes Surg 2009; 19:553-9.

34. Shermak MA, Rotellini-Coltvet LA, Chang D. Seroma development following body contouring surgery for massive weight loss: patient risk factors and treatment strategies. Plast Reconstr Surg 2008;122:280-8.

35. Hng KN, Ang YS. Overview of bariatric surgery for the physician. Clin Med (Lond) 2012;12:435-40. 